PontifícIA UNIVERSIDADE CATÓLICA dO RIO DE JANEIRO

Eficiência do Linkedln nos processos de recrutamento e seleção em empresas de consultoria de $\mathbf{R H}$

Bárbara Rodrigues Occhiuzzi

Trabalho de Conclusão de Curso

Centro de CIÊnCIAS SOCIAIS - CCS

DEPARTAMENTO DE ADMINISTRAÇÃO

Graduação em Administração de Empresas 
Bárbara Rodrigues Occhiuzzi

\title{
Eficiência do Linkedln nos processos de recrutamento e seleção em empresas de consultoria de RH
}

\author{
Trabalho de Conclusão de Curso
}

Trabalho de Conclusão de Curso, apresentado ao programa de graduação em Administração da PUC-Rio como requisito parcial para a obtenção do titulo de graduação em Administração.

Orientador(a) : Edmundo Eutrópio

Rio de Janeiro, novembro de 2021. 


\section{Agradecimentos}

Gostaria de agradecer e dedicar essa dissertação às seguintes pessoas:

Minha família, especialmente meu pai Roberto e minha mãe Denise, que sempre me apoiaram e acreditaram em mim.

Meus amigos, por toda a ajuda e parceria durante esses 4 anos de graduação.

Meu orientador, Edmundo Eutrópio, que se dedicou a me ajudar nesse processo.

À mim mesma, que me dediquei durante todos esses anos, sempre dando o máximo de mim. 


\title{
Resumo
}

Esse trabalho tem como objetivo entender em que condições o Linkedln se torna adequado para recrutar profissionais e, consequentemente, quando essa plataforma acaba não sendo eficiente na busca por candidatos no mercado. O estudo mapeou os possíveis usos do Linkedln e suas funcionalidades, tanto para os recrutadores quanto para os usuários e levantou informações dos recrutadores em relação a eficiência da plataforma. Foram feitas 6 entrevistas qualitativas e semiestruturadas com consultores de recrutamento e seleção para atingir o objetivo do artigo. Ao término de estudo, constatou-se que o Linkedln é, atualmente, o recurso mais utilizada e mais eficiente nos processos de recrutamento e seleção, entretanto, existem algumas situações específicas em que ele acaba não funcionando como ferramenta de busca de profissionais no mercado.

Palavras- chave: Recrutamento e Seleção, Linkedln, Consultoria, Recrutadores.

\begin{abstract}
This work aims to understand under what conditions Linkedln is suitable for recruiting professionals and, consequently, when this platform ends up not being efficient in the search for candidates in the market. The study mapped the possible uses of Linkedln and its functionalities, for both recruiters and users, and gathered information from recruiters regarding the platform's efficiency. Six qualitative and semi-structured interviews were conducted with recruitment and selection consultants to achieve the objective of the article. At the end of the study, it was found that Linkedln is currently the most used and most efficient resource in the recruitment and selection processes, however, there are some specific situations in which it ends up not working as a search tool for professionals in the market.
\end{abstract}

Key-words: Recruitment and Selection, LinkedIn, Consulting, Recruiters. 


\section{Sumário}

1. O tema e o problema de estudo 1

1.1. Introdução ao tema e ao problema do estudo 1

1.2. Objetivo do estudo 2

1.3. Objetivos intermediários do estudo 2

1.4. Delimitação e foco do estudo 2

1.5. Relevância do Estudo 3

2. Revisão de literatura 4

2.1. Recrutamento e Seleção 4

2.2. Consultoria de Recrutamento e Seleção 5

2.3. O Recrutamento Online (E-Recrutamento) 6

$\begin{array}{ll}\text { 2.4. Linkedln } & 7\end{array}$

3 . Métodos e procedimentos de coleta e de análise de dados do estudo 9

$\begin{array}{ll}\text { 3.1. Tipo de pesquisa } & 9\end{array}$

3.2. Procedimentos e instrumentos de coleta de dados utilizados no $\begin{array}{ll}\text { estudo } & 10\end{array}$

3.3. Formas de tratamento dos dados coletados para o estudo 11

3.4. Limitações do método 11

4. Apresentação e análise dos resultados 12

4.1. Eficiência do Linkedln no geral 12

4.2. Falhas do Linkedln 13

4.3. Quando o Linkedln não é eficiente 13

4.4. Outros recursos e ferramentas 15

5. Conclusões e recomendações para novos estudos 17

6. Referências Bibliográficas 20

$\begin{array}{ll}\text { Apêndice } 1 & 23\end{array}$ 
Apêndice 2

Apêndice 3

Apêndice 4 31

Apêndice 5

Apêndice 6

\section{Lista de Tabelas}

Tabela 1: Características dos entrevistados. 


\section{O tema e o problema de estudo}

\subsection{Introdução ao tema e ao problema do estudo}

Para que uma empresa consiga atingir seus objetivos no mercado necessitase da força de trabalho de pessoas eficientes e dispostas a combinar seus esforços visando o melhor para a organização. Nesse sentido, o processo de recrutamento e seleção torna-se importante para que se encontre o profissional ideal para uma posição em aberto e para que ocorra uma contratação bemsucedida.

Com o avanço da tecnologia, os processos de recrutamento e seleção foram migrando cada vez mais para o mundo digital, desde a divulgação da vaga até a condução desses processos. Nesse contexto, as redes sociais começaram a ser usadas como ferramenta administrativa pelas empresas visto que, estas, aproximam em tempo real, todas as partes interessadas da organização como os clientes, os colaboradores, os acionistas e a sociedade (Alméri, Mendes, Martins, \& Luglio, 2014 apud Alexandra, 2017).

O Linkedln, rede social mais utilizada no contexto profissional (Nikolaou, 2014), será a ferramenta de estudo nesse artigo pois, de acordo com o estudo de Nikolaou (2014) comparando quantitativamente a eficácia do Linkedln e do Facebook nos processos de Recrutamento e Seleção, obteve-se um resultado de que o Linkedln é mais eficaz que o Facebook para fins de recrutamento.

De acordo com Osman (2021) e uma pesquisa feita sobre as estatísticas e fatos do Linkedln, existem mais de 575 milhões de usuários conectados na plataforma, sendo 260 milhões ativos mensalmente no mundo todo. No Brasil, esse número passa a ser equivalente a mais de 34 milhões de usuários.

Entretanto, vale ressaltar que desses usuários, apenas $40 \%$ acessam-na todos os dias e com um certo grau de moderação, visto que os perfis passam cerca de 17 minutos mexendo no Linkedln, por mês. 
Vale ressaltar que mais de 20 milhões de empresas estão listadas na plataforma, com mais de 14 milhões de empregos em aberto, fazendo com que $90 \%$ dos recrutadores utilizem regularmente o Linkedln no processo de R\&S (Osman, 2021).

Além disso, foi constatado o número de pessoas que fizeram uma entrevista através do Linkedln chega a 122 milhões no mundo todo, contabilizando um total de 35,5 milhões de contratados por uma pessoa com quem se conectaram na plataforma (Osman, 2021).

Nesse sentindo, entendendo que a ferramenta é relevante para os processos de recrutamento e seleção e é utilizada pela maioria dos recrutadores no mundo todo, esse estudo investiga a seguinte pergunta problema: existe alguma situação ou condição em que o Linkedln acaba não sendo a ferramenta adequada para recrutar profissionais?

\subsection{Objetivo do estudo}

Nesse contexto, esse estudo tem como objetivo entender em que condições o Linkedln se torna adequado para recrutar profissionais e, consequentemente, quando essa plataforma acaba não sendo eficiente para esse trabalho.

\subsection{Objetivos intermediários do estudo}

Para atingir o objetivo do estudo, foi necessário mapear os possíveis usos do Linkedln e suas funcionalidades, tanto para os recrutadores quanto para os usuários. Além disso, também foi necessário levantar informações dos recrutadores em relação a eficiência do Linkedln nos processos de R\&S e quando o uso do Linkedln não atingiu suas expectativas.

\subsection{Delimitação e foco do estudo}

Esse estudo tem como foco o uso da plataforma Linkedln para processos de recrutamento e seleção, observando apenas usuários maiores de 18 anos no Brasil em 2021. Não é abordado pelo estudo recrutadores que não atuam em consultorias de R\&S e usuários menores de 18 anos que não são brasileiros. 


\subsection{Relevância do Estudo}

Esse estudo assume importância a medida que as consultorias de RH estão, cada vez mais, dedicando uma maior parte do seu tempo estabelecendo contatos pessoais através das redes sociais do que publicando anúncios em jornais (Faroldi, 2007).

A princípio, existem três principais objetivos ao se utilizar o Linkedln: acompanhar conteúdos, fazer networking e buscar emprego. Nesse contexto, esse estudo é importante para os recrutadores, a medida que conseguirão entender, junto a outros recrutadores, quando a plataforma não satisfaz seus objetivos e o que fazer quando isso acontece.

Além disso, ele é importante também para os usuários do Linkedln que poderão levantar informações importantes sobre como e quando os recrutadores utilizam a plataforma para achar profissionais e quando essa ferramenta não satisfaz o objetivo do processo R\&S.

O estudo é importante também para as empresas que contratam as consultorias para fazer seus processos de R\&S a medida que elas terão mais informações sobre a forma de trabalho das consultorias e poderão escolher a que melhor satisfará seus objetivos.

Por outro lado, o estudo também é de importante valor para as plataformas de $R \& S$ e outras redes sociais profissionais, visto que estas irão entender onde o Linkedln não é a opção adequada para o R\&S e poderão atender as demandas que não foram sanadas pela ferramenta. 


\section{Revisão de literatura}

Neste capítulo são apresentados e discutidos aspectos conceituais e estudos relacionados ao tema e estudo em investigação e que servirão de base para a análise realizada.

\subsection{Recrutamento e Seleção}

O Recrutamento e Seleção (R\&S), como um todo, na visão de Bartram (2000), é classificado em três etapas. A primeira, conhecida como atração, é como conquistar o candidato para a vaga disponível. Logo em seguida, analisando o perfil dos candidatos, ocorre a filtragem dos mesmos e, a última e terceira etapa é o momento de identificar e escolher, dentre os candidatos, quem é o profissional mais adequado para a oportunidade.

O recrutamento pode ser feito de forma interna, quando os funcionários da "casa" demonstram, através de sua dedicação, desempenho e resultados, que estão aptos para disputar a vaga disponível (Sousa et al., 2006). Como vantagem, pode-se destacar o baixo custo, entretanto, a falta de um colaborador novo para a organização pode ser considerada uma desvantagem.

Já o recrutamento externo, para Chiavenato (2009), advém da necessidade de a vaga ser preenchida por alguém que ainda não é colaborador da organização. Nesse momento, a empresa organiza dinâmicas, testes e entrevistas com o objetivo de conhecer o candidato e apresentar as praticas e politicas da mesma.

Universidades e escolas, banco de dados de currículos dos interessados, indicações, cartazes nas empresas e consultorias de recrutamento são alguns dos canais de recrutamento externo existentes (Caetano \& Vala, 2007).

Ao escolher a modalidade de recrutamento externo, a empresa deve analisar o mercado e escolher recrutar de forma direta ou utilizando serviços de consultorias especializadas. Os autores Câmara, Guerra e Rodrigues (2010), acreditam que as organizações devem recorrer a empresas de consultorias para cargos mais altos visto que os recrutadores possuem conhecimento necessário para encontrar candidatos desse nível e apresentar-lhes as oportunidades de emprego. 


\subsection{Consultoria de Recrutamento e Seleção}

A consultoria de Recrutamento e Seleção é uma empresa que tem como função fornecer uma parte ou todo o serviço de recrutamento e seleção a entidades externas (Meskanick, 2009). Trabalha-se com uma taxa de serviço e, a partir dos critérios informados pela empresa cliente e das necessidades identificadas, a consultoria faz a identificação de candidatos qualificados para determinada posição (Fish \& Macklin, 2004).

O processo de recrutamento e seleção feito com consultorias é dividido em algumas etapas, começando pelo recrutamento. Nesse momento, para Lacombe (2011), inicia-se a definição do perfil da vaga fornecida, na maioria das vezes, pela empresa que contratou a consultoria e, em outras situações, há uma construção que envolve tanto as exigências da organização quanto pesquisas dos consultores. Ainda no processo de recrutamento, o segundo passo é a divulgação da posição para mostrar para o mercado que certo profissional está sendo requisitado e chamar a atenção daqueles que estão disponíveis.

Após a divulgação da posição, a consultoria recebe vários currículos que, não necessariamente, estarão alinhados com os requisitos da vaga. Nesse momento, os consultores têm o papel de fazer uma triagem desses currículos, selecionando apenas aqueles que estão compatíveis com o perfil desejado. Além do recebimento de candidaturas, os consultores também realizam pesquisas em bancos de currículos (principalmente por meios digitais) à fim de encontrar 0 profissional.

O segundo passo no processo é a s seleção, começando pelo primeiro contato entre o consultor e o candidato. Essa etapa normalmente é feita por telefone e o consultor fará uma sondagem superficial para entender experiências profissionais, pretensão salarial, remuneração atual e interesse na posição ofertada.

Logo após fazer um mapeamento, o consultor seleciona os perfis aderentes e agenda uma entrevista com a empresa para conhecer mais sobre os candidatos. Em alguns casos, além de uma conversa direta, também são feitos testes psicológicos. Nesse momento, é necessário identificar as fontes mais produtivas para encontrar os candidatos que atenderão às necessidades da empresa. (Carvalho, Passos e Saraiva, 2008). 
Por último, junto com um material enviado pela consultoria contendo informações sobre os candidatos, a empresa toma a sua decisão acerca de quem será o profissional contratado para a posição.

\subsection{O Recrutamento Online (E-Recrutamento)}

Com a evolução tecnológica, econômica e social, o recrutamento passou por grandes mudanças ao longo do tempo até chegar da forma como é atualmente (Peretti, 2007). Com o avanço da internet, ocorreu uma transição do recrutamento tradicional para um processo rápido, dinâmico e moderno conhecido como erecrutamento (Dhamija, 2012).

O e-recrutamento, para Almeida (2014), contribui para a divulgação de ofertas de emprego a nível global e proporciona ao candidato uma oportunidade de se candidatar em vagas de qualquer lugar do planeta. $O$ uso do e-recrutamento no ambiente empresarial gerou uma automatização do processo, permitindo ultrapassar barreiras geográficas, eliminar o excesso do papel e proporcionar autonomia para os recrutadores realizarem mais de uma etapa ao mesmo tempo (Coronas \& Olivas, 2015).

De acordo com Cappelli (2001), o e-recrutamento acontece em 3 etapas, sendo a primeira a atração dos futuros candidatos. Nesse momento, há investimentos em anúncios na internet para encontrar potenciais interessados nas oportunidades disponíveis. A seleção é a segunda etapa e ela deve ser planejada corretamente para que os objetivos da empresa sejam atendidos de modo eficiente e eficaz. Por fim, o contato direto com o candidato, na intenção de que ele não fique muito tempo sem resposta e acabe optando por outra oportunidade.

Para Thomas e Ray (2000), o e-recrutamento é um processo que inclui vários e diferentes tipos de ferramentas e recursos e variadas formas de usá-los, deixando de ser uma técnica específica apenas. As principais ferramentas utilizadas incluem os bancos de currículos (empresas comerciais), sites especializados em oferta de trabalho, salas de bate-papo, fóruns de discussão, além dos próprios websites das empresas.

Existem algumas empresas que estão mais avançadas e contam com uma página específica para recrutamento nos seus sites, servidores mais poderosos e banco de dados com vários currículos. Entretanto, ainda existe uma grande resistência das pessoas em relação a utilização de tais ferramentas por parte das pessoas. Nesse contexto, é preciso que os sistemas sejam plenamente utilizados 
e de maneira eficiente para que alguns processos deixem de ser ultrapassados. A tecnologia oferece economia e rapidez, mas só para quem sabe usá-la direito (Vieira, 2010)

Segundo dados da Eurostat (2017), 68\% das empresas da União Europeia que empregavam 250 pessoas ou mais, usavam algum tipo de rede social para fazer o processo de recrutamento. Nesse contexto, Davison et al. (2012) focou seu estudo na forma como a Internet mudou a triagem e o recrutamento de candidatos, especialmente através das pesquisas de perfis de redes sociais, como o Facebook e o Linkedln.

\subsection{Linkedln}

O Linkedln foi criado em 2002, mas lançado oficialmente em 2003 por um grupo de 5 amigos na sala de estar do co-fundador Reid Hoffman nos Estados Unidos. É uma rede de contatos profissionais que tem como objetivo aumentar o networking e possibilitar que seus usuários encontrem oportunidades de empregos (Sanchez, Granado \& Antunes, 2014).

O Linkedln disponibiliza modelos para a auto apresentação que seguem os formatos do currículo (Papacharissi, 2009), permitindo a conexão de profissionais, promoção de suas competências, compartilhamento de conhecimento e experiências e planejamento de futuras etapas da carreira (Zide et al., 2014). Além disso, a rede social possibilita que os recrutadores pesquisem por palavras-chave para identificar pessoas de interesse (Ollington et al., 2013).

A rede social é de uso gratuito, porém, disponibiliza versões pagas que contém funcionalidades avançadas, utilizadas especialmente por empresas de recrutamento (Caramez, 2013).

Algumas ferramentas que a conta avançada permite são: acesso a mensagens diretas para usuários que ainda não estão nas nossas conexões, acesso ao organizador de perfis em pastas, monitoramento de usuários importantes, aumento do numero de visualizações de perfis por pesquisa e acesso a mais detalhes sobre quem visualizou o seu perfil (Caramez, 2013).

De acordo com Caramez (2017), os Estados Unidos, com 132.5 milhões de conectados, é o pais que domina o uso do Linkedin. Em segundo lugar, com 38.5 milhões de conexões, encontra-se a China e o Brasil em terceiro lugar com 28 milhões de usuários. 
Segundo a revista Forbes (Adams, 2013), a rede social considerada uma das que tem maior sucesso e maior utilização por recrutadores e por profissionais que procuram emprego na Internet é o Linkedln. Além disso, de acordo com Dekay (2009), está sendo verificado um aumento da presença de candidatos em comunidades online para se apresentarem e impressionares os potenciais empregadores. Isso ocorre devido ao grande número de empresas que estão utilizando plataformas na internet para procurar candidatos para funções em suas empresas. Esta tendência é confirmada no Linkedln ao observar que o aumento exponencial do o número de membros desta rede social, nos últimos anos (Gerard, 2011).

De acordo com Fernandes (2014), a rede social mais utilizada para o recrutamento de candidatos é o Linkedln, tendo sido recorrido, em 2011, por 80\% das grandes empresas, em comparação aos $50 \%$ que recorreram ao Facebook e aos 45\% que recorreram ao Twitter. Para Gomes (2011), a grande vantagem do Linkedln é que ele proporciona, uma vasta rede de contatos profissionais de várias áreas para os candidatos enquanto, para as empresas, a rede social apresenta uma variedade de candidatos com possibilidade de visualização dos seus currículos quase que instantaneamente, visto que o perfil apresentado pelo candidato é o seu próprio currículo, facilitando assim o processo de recrutamento no sentido de perceber se aquele perfil tem as competências necessárias para a oferta de emprego em questão.

Em relação a utilização do Linkedln é necessário ter atenção em alguns aspetos importantes na divulgação do perfil, como colocar uma fotografia profissional de perfil, fazer um resumo do percurso profissional, que deve ter em torno de 5 a 6 linhas, fazer com que as recomendações sejam competências ou descrição de forma detalhada sobre aspetos importantes da pessoa e até mesmo, se for colega de trabalho, se gostou de trabalhar com essa pessoa (Sanchez, Granado \& Antunes, 2014). 


\section{Métodos e procedimentos de coleta e de análise de dados do estudo}

Este capítulo pretende informar sobre as diversas decisões a cerca da forma como este estudo foi realizado.

\subsection{Tipo de pesquisa}

Nesse artigo, com o objetivo de entender em que condições o Linkedln se torna adequado para recrutar profissionais e, consequentemente, quando essa plataforma acaba não sendo eficiente para esse trabalho, fez-se uma pesquisa classificada com base na taxonomia de Vergara (1990), a qual qualifica a pesquisa quanto aos fins e quanto aos meios.

Quanto aos fins, a pesquisa é exploratória visto que ela explora um tema novo, não tendo sido verificado estudos que abordem a eficácia do Linkedln considerando diferentes situações e estilos de vaga.

Em relação aos meios, a pesquisa foi bibliográfica e de campo. Bibliográfica porque foi realizado uma investigação para auxiliar na fundamentação teóricometodológica do trabalho sobre os seguintes temas: a área de recrutamento e seleção, a evolução do recrutamento online, o recrutamento dentro de consultorias especializadas e o próprio Linkedln e suas ferramentas de uso. Além disso, a pesquisa teve um levantamento de campo, dentro de uma abordagem qualitativa, onde coletou dados primários de headhunters de uma consultoria de recrutamento e seleção. 


\subsection{Procedimentos e instrumentos de coleta de dados utilizados no estudo}

$\mathrm{Na}$ pesquisa bibliográfica, os dados foram coletados através de livros, revistas especializadas, teses e dissertações com dados pertinentes ao assunto. O objetivo dessa pesquisa é ter como resultado uma melhor compreensão sobre a relação do Linkedln com o processo de recrutamento e seleção em consultorias especializadas.

Já no campo, a coleta de dados foi realizada através de uma entrevista semiestruturada, ou seja, foi elaborado um roteiro com perguntas pertinentes sobre o Linkedln e sua eficácia, porém, tanto os entrevistados quanto o entrevistador tiveram a liberdade de alterar a ordem das questões ou introduzir novas questões à medida que fosse necessário. Essa entrevista foi feita online, via Google Meet, com headhunters de uma consultoria especializada para obter as seguintes informações:

a. Como você considera a eficiência do Linkedln para os processos de $R \& S$;

b. Quais os seus objetivos com o uso do Linkedln;

c. Quais os níveis de posição que você recruta;

d. Quais são os piores problemas que o Linkedln tem para o processo de $R \& S$;

e. A possibilidade de, em algum processo ou alguma situação, o Linkedln não tenha sido eficiente para encontrar/filtrar candidatos;

f. Outra plataforma ou recurso utilizado para filtrar candidatos no processo de R\&S quando o Linkedln não satisfaz.

Ressalta-se que antes de toda entrevista ter sido iniciada, foi explicado ao entrevistado o objetivo e a relevância da pesquisa e a importância de sua colaboração. Foram feitas, no geral, perguntas abertas para captar mais informações e possíveis mudanças entre cada entrevistado e perguntas fechadas para sanar dúvidas mais pontuais que poderiam acabar não sendo comentadas pelos entrevistados. 


\subsection{Formas de tratamento dos dados coletados para o estudo}

Com o objetivo de tirar o melhor proveito dos dados coletados, todas as entrevistas foram gravadas com autorização dos entrevistados e foram transcritas para melhor análise. As informações obtidas nas entrevistas foram comparadas entre si e entre o material bibliográfico estudado nesse artigo.

\subsection{Limitações do método}

O método escolhido para a pesquisa possui algumas limitações e fragilidades em relação a coleta e ao tratamento dos dados.

A maior fragilidade referente a coleta de dados é a quantidade de entrevistas, porém vale destacar que elas foram feitas em uma abordagem qualitativa. O mercado de consultorias de recrutamento e seleção no Brasil é enorme e possui um número grande de headhunters, para ter uma visão do mercado inteiro teria que ser feito uma ampla pesquisa com abordagem quantitativa.

Já em relação ao tratamento dos dados, a maior fragilidade encontrada é em o próprio autor desse artigo trabalhar no segmento de recrutamento e seleção em uma consultoria de capital humano, tendo assim, um viés sobre as informações coletadas. 


\section{Apresentação e análise dos resultados}

Este capítulo, organizado em 4 seções, apresenta e discute os principais resultados alcançados, analisa e discute suas implicações e produz sugestões sobre o estudo previamente selecionado. Em cada seção consta a resposta da pergunta feita e uma análise sobre as informações coletadas.

Foram entrevistados 6 consultores de recrutamento e seleção e segue abaixo quadro com algumas características sobre os entrevistados:

Tabela 1: Características dos entrevistados

\begin{tabular}{|c|c|c|c|c|}
\hline Entrevistado & Sexo & Idade & Tempo como Recrutador & Segmento que atua \\
\hline A & Feminino & 38 anos & 14 anos & Indústrias e Serviços \\
\hline B & Feminino & 26 anos & 3 anos & Private Equity e Venture Capital \\
\hline C & Masculino & 40 anos & 13 anos & Energia e Infraestrutura \\
\hline D & Masculino & 25 anos & 3,5 anos & Tecnologia \\
\hline E & Feminino & 21 anos & 1 ano & Tecnologia \\
\hline F & Feminino & 35 anos & 2 anos & Agronegócio \\
\hline
\end{tabular}

Fonte: Elaborada pela autora do artigo.

\subsection{Eficiência do Linkedln no geral}

Todos os entrevistados acreditam que o Linkedln é a rede mais eficiente para recrutamento e seleção existente hoje no mercado visto que ela permite encontrar profissionais, tendo acesso a algumas informações de seu perfil, ao mesmo tempo que permite que esses profissionais se conectem com os recrutadores.

A entrevistada $B$ relatou que, para ela, o Linkedln tem uma eficiência de $80 \%$, considerando que ele permite fazer contato direto com as pessoas e visualizar seus perfis de forma a encontrar informações que ajudarão na hora da entrevista.

Como foi relatado anteriormente nesse artigo, o Linkedln, de acordo com Fernandes (2014), é a rede social mais utilizada para recrutamento de candidatos. Mesmo tendo suas falhas e gaps, os entrevistados concordam que a ferramenta é a melhor ferramenta para encontrar pessoas visto que é onde se tem a maior quantidade de pessoas dispostas a serem abordadas. 
Vale ressaltar, que todos os entrevistados usam o Linkedln Premium, tendo acessos mais avançados sobre a plataforma.

\subsection{Falhas do Linkedln}

Como citado anteriormente nesse artigo, o Linkedln possui versões pagas e todos os entrevistados utilizam a versão Premium da plataforma, dando a eles ferramentas mais avançadas. Sendo assim, todas as falhas destacadas pelos entrevistados estão baseadas em suas experiências com o uso do Linkedln Premium.

A falha mais comentada foi o limite de conexões que você pode enviar por dia, fazendo com que ele tenha que aguardar o próximo dia para continuar abordando possíveis candidatos. $O$ trabalho do headhunter é baseado em volume de profissionais que ele aborda, tendo essa limitação por parte do Linkedln, acaba atrapalhando o rendimento do seu trabalho.

Outro problema comentado pelos entrevistados é a eficiência dos filtros para busca de perfis. Foi relatado que, ao fazer buscas com muitos filtros ao mesmo tempo, pode acabar mostrando perfis que não são compatíveis com o esperado.

A entrevistada A, citou como uma falha do Linkedln, não conseguir fazer determinadas buscas como filtrar profissionais por gênero, $\mathrm{PcD}$ ou cor da pele. É frequente, no mundo atual, os clientes pedirem para os headhunters buscarem profissionais que se enquadrem na minoria, porém, o Linkedln ainda não permite que se faça esse tipo de filtro.

Outras falhas foram citadas pelos entrevistados, como o limite de mensagens que podem ser enviadas no mês e o limite de caracteres que pode ter a primeira mensagem que você envia para um perfil.

Avaliando todos os problemas citados, entende-se que, teria como o Linkedln ser uma ferramenta melhor do que ela já é, mas nenhuma falha da plataforma atrapalha por completo o trabalho do recrutador a ponto de ele optar por usar outro recurso.

\subsection{Quando o Linkedln não é eficiente}

Em relação ao objetivo do artigo, foram coletadas informações que mostram que o Linkedln acaba não sento tão eficiente em algumas situações no processo 
de R\&S. Foram identificados gargalos da ferramenta referentes a sua eficiência na busca por profissionais no mercado de trabalho.

Um dos maiores gargalos citados nas entrevistas foi em relação ao nível do profissional. Foi solicitado que os entrevistados dessem uma nota, em uma escala de 0 a 5, sobre a eficiência do Linkedln para recrutar alguns níveis de senioridade. De acordo com os entrevistados, a ferramenta é $100 \%$ eficiente para recrutar gerentes e coordenadores. Já para analistas seniores e plenos, a ferramenta acaba não sendo totalmente eficiente, mas ainda assim, os entrevistados acreditam numa eficiência média de $85 \%$. Diminuindo para analistas juniores, a eficiência passa a ser $60 \%$, enquanto para estagiários o numero cai para $40 \%$, de acordo com os entrevistados.

A entrevistada $F$ citou que, para ela, muito mais que a senioridade do cargo, o que importa é a área de atuação do profissional. Existem algumas áreas em que a pessoa, desde a faculdade, já é apresentada e familiarizada com o Linkedln, enquanto em outras áreas demora para a pessoa conhecer a plataforma ou acaba não conhecendo.

Sendo assim, identificou-se que o Linkedln é mais eficiente para recrutar profissionais de áreas como o administrativo, financeiro e recursos humanos. Profissionais de áreas mais operacionais ou de baixo nível corporativo, como vendedor de loja, peão de obra, posições de produção fabril, entre outras posições, são mais difíceis de serem encontrados no Linkedln.

Outra área onde o Linkedln acaba não sendo tão eficiente é a área de tecnologia. Entende-se que muitos profissionais tech, especialmente de cargos mais operacionais, como desenvolvedores, não se encontram conectados na plataforma, aumentando a dificuldade de recruta-los através do Linkedln.

Outro gap identificado através das entrevistas, é o segmento da empresa em que o profissional atua. A entrevistada $F$ é uma recrutadora focada no segmento do agronegócio e explicou a dificuldade que é encontrar profissionais agro no Linkedln. Ela informou que muitas empresas não estão cadastradas no Linkedln e, consequentemente, muitos profissionais também não utilizam a plataforma pois a cultura do uso da plataforma ainda não é explorada da melhor forma nesse segmento.

Uma outra situação, citada pela entrevistada $B$, que também possui um certo grau de dificuldade na hora do processo de recrutamento e seleção, é buscar por profissionais em regiões mais remotas. Saindo do eixo Sul/Sudeste e indo mais para o Norte, existem muitos lugares onde a tecnologia ainda é fraca, limitando o 
número de pessoas cadastradas no Linkedln e, consequentemente, aumentado a dificuldade de buscar profissionais para essas regiões na plataforma.

Foi possível identificar alguns gaps do Linkedln e, analisando todos eles em conjunto, entende-se que o maior problema é a falta de conhecimento e interesse da parte dos profissionais em relação ao uso da plataforma. Hoje, no Brasil, de acordo com o próprio Linkedln, existem 51 milhões de usuários ativos na plataforma. Considerando que o Brasil tem uma população estimada de acordo com o IBGE (2019) de mais de 212,6 milhões de pessoas e 40 milhões de brasileiros não tem acesso a internet, o número de usuários do Linkedln representa, aproximadamente, $29,6 \%$ da população Brasileira com acesso a internet.

Sendo assim, mesmo sendo um número alto e que aumenta cada vez mais, ainda existem muitos profissionais que não estão no Linkedln, seja por falta de conhecimento sobre a importância ou uso da plataforma, seja por falta de interesse ou qualquer outro motivo. Com isso, os recrutadores acabam buscando esses profissionais de outra forma, usando outros recursos e ferramentas.

\subsection{Outros recursos e ferramentas}

Diante da ineficiência do Linkedln em alguns processos de $R \& S$, os entrevistados relataram outros meios que eles utilizam ou já utilizaram para encontrar possíveis candidatos. Foram citados sites de procura de emprego, como Vagas.com e InfoJob. Além disso, entrevistados que já trabalharam em outras consultorias, identificam o próprio bando de dados da empresa como uma fonte de profissionais.

Alguns entrevistados citaram também outras redes sociais como Facebook e Instagram, não como ferramenta para encontrar candidatos, mas sim para abordá-los de forma que a resposta venha com mais agilidade, após já terem visto seu perfil no próprio Linkedln.

Outro meio citado pelos entrevistados é o presencial. Antes da pandemia do Covid-19, existiam feiras, palestras e workshops onde os headhunters poderiam ir para fazer networking e prospectar possíveis candidatos. Além disso, para posições mais operacionais como caixa e atendente de lojas, os consultores citaram ir nas lojas e shoppings em busca de profissionais e indicações.

Além desses recursos, a indicação e networking off-line também é bem utilizada pelos recrutadores nesses casos de maior dificuldade. Assim como a 
mídia off-line, como anúncios impressos colocados em lugares na rua ou em estabelecimentos.

Já no segmento de tecnologia, foi citado o BitHub, uma espécie de banco de dados de programação, como possível substituto do Linkedln em casos de dificuldade. Entretanto, ele é utilizado muito raramente devido a sua dificuldade de manuseio. Outras soluções para o segmento de tecnologia, citadas pelo entrevistado D, são os portais de divulgação de vagas como Profissionais TI e Geek Hunter.

Observa-se então que existem outros caminhos, além do Linkedln, para buscar profissionais no mercado, porém, eles não são tão utilizados e tão eficientes quando a rede social. Como citado anteriormente nesse artigo, de acordo com Fernandes (2014), o Linkedln foi a rede social mais utilizada para recrutamento de candidatos em 2011. 


\section{Conclusões e recomendações para novos estudos}

O objetivo desse artigo foi entender em que condições o Linkedln se torna adequado para recrutar profissionais e, consequentemente, quando essa plataforma acaba não sendo eficiente para esse trabalho.

Para aprofundar a analise pretendida, investigou a perspectiva dos autores como, Fernandes (2014), Nikolaou (2014) e Caramez (2017), que citam em seus trabalhos a importância e relevância do Linkedln nos processos de recrutamento e seleção.

$\mathrm{Na}$ intenção de atingir os objetivos pretendidos, realizou-se pesquisa bibliográfica ao se estudar o processo de recrutamento e seleção nas consultorias e as ferramentas do Linkedln e seus dados, e pesquisa de campo. Foram feitas 6 entrevistas qualitativas semiestruturadas com recrutadores de consultorias de $R \& S$.

Observando os resultados obtidos através das entrevistas, pode-se entender que o Linkedln, na maioria das vezes, satisfaz o objetivo do consultor no processo de recrutamento e seleção. Entretanto, em alguns casos mais específicos ele acaba não satisfazendo, porém, não devido as suas próprias ferramentas de busca, mas sim pela falta de conhecimento ou interesse de certos profissionais na plataforma.

Uma situação que comprova essa afirmação é a busca por profissionais de níveis mais inferiores, como estagiários e analistas juniores, que podem ainda não estar familiarizados com a plataforma.

Outra situação em que os profissionais podem não conhecer o Linkedln e por isso acaba se tornando um gap para a plataforma na parte de recrutamento e seleção é a busca por profissionais de uma área mais operacional, como produção fabril, vendedor de loja e peão de obra.

Além dessas situações, posições do segmento de tecnologia e de agronegócio também são exemplos de buscas em que o Linkedln não satisfaz da melhor maneira possível pelo mesmo motivo citado anteriormente sobre a falta de cultura desses profissionais no uso da plataforma. 
Também se discutiu a busca por profissionais de regiões remotas que acaba sendo difícil de ser feita através do Linkedln devido ao pouco acesso a internet nesses locais.

Por outro lado, a investigação apontou outros meios para encontrar esses profissionais do mercado. Entre eles estão sites de divulgação de vagas, outras redes sociais, como Instagram e Facebook, mídia off-line, indicação, feiras, palestras e workshops.

Pode-se concluir que o estudou respondeu aos questionamentos do artigo e foi relevante para os recrutadores, para os usuários do Linkedln, para as empresas clientes das consultorias e para as outras plataformas de R\&S.

A relevância para os recrutadores foi de mostrar para eles outros caminhos e outras possibilidades de buscar profissionais que não se encontram ou se encontram com dificuldade no Linkedln. Cada recrutador respondeu com um recurso diferente, ou seja, entende-se que nem todos conheciam ou imaginavam as formas de encontrar profissionais relatadas pelos outros recrutadores, ocorrendo assim uma troca de informações valiosas entre eles.

Já para os usuários do Linkedln, o estudo foi relevante pois eles conseguiram entender quais perfis de profissionais que os recrutadores buscam na plataforma. Além disso, sendo um profissional que se enquadra nas situações relatadas pelos headhunters como de dificuldade de busca, conseguiram identificar quais outras plataformas ou recursos eles devem se inserir para conseguir emprego.

Para as empresas que contratam as consultorias, entender as diferentes formas de busca de profissionais no mercado e quando o Linkedln não é eficiente, faz com que elas consigam escolher a consultoria com base nas suas ferramentas de busca atrelado ao tipo de profissional que ela está querendo contratar. Ou seja, se a empresa está buscando um perfil que é difícil de ser encontrado no Linkedln, ela poderá optar por alguma consultoria que usa o seu próprio banco de talentos ou outro recurso para essa etapa do processo.

Além disso, o estudo também foi importante para as outras plataformas citadas pelos entrevistados como substitutos do Linkedln, visto que elas conseguiram entender quando o Linkedln não gera valor, podendo atender as demandas não sanadas pela ferramenta. Como exemplo, o Vagas.com, entendendo que o Linkedln não atende tanto aos níveis de estagiários e analistas juniores, pode focar seu trabalho para esse público. 
Entende-se que, para que o Linkedln se torne uma plataforma cada vez mais eficiente, ela deve ser mais reconhecida e mais usada entre todos os profissionais, independente do nível hierárquico ou segmento que atua. Ou seja, é interessante que o Linekdln trabalhe mais o seu branding no universo de pessoa física, mostrando seus objetivos e sua relevância para que esse público conheça e tenha interesse de ser usuário da plataforma.

Como desdobramentos futuros, essa linha de estudo pode ser desenvolvida através de investigação sobre os não usuários de Linkedln, de forma a descobrir quem são essas pessoas e entender porque não estão conectados na plataforma, se é pela falta de conhecimento, falta de interesse, por não achar tão relevante ou por qualquer outro motivo.

Outra investigação interessante que poderia ser desenvolvida para complementar o estudo desse artigo seria mapear os usuários do Linkedln, quais são seus cargos, em que segmentos eles atuam, com que frequência eles utilizam a plataforma e quais são seus objetivos ao usá-la.

Dessa forma, o estudo ficaria mais completo a medida que entenderia não apenas o lado do recrutador, mas também entenderia as motivações e perfis dos usuários do Linkedln e dos não usuários da plataforma. 


\section{Referências Bibliográficas}

ADAMS, S. (2013). New survey: Linkedln more dominant than ever among job seekers and recruiters, but Facebook poised to gain. Forbes, 10, 28-29

ALMEIDA, H. (2014). Manual de Gestão de Recursos Humanos da Estratégia a Prática. (2aed.). Lisboa: Sílabas \& Desafios.

BARTRAM, D. (2000). Internet Recruitment and Selection: Kissing Frogs to Find Prince. Internacional Journal of Selection and Assessment,8(4),261-274.

CAETANO, A. \& Vala, J. (2007). Gestão de Recursos Humanos: Contextos, Processos e Técnicas. (3a ed.). Lisboa: Rh Editora.

CÂMARA, P., Guerra, P. \& Rodrigues, J. (2010). Novo Humanator. Recursos Humanos e Sucesso Empresarial. (4a ed.). Lisboa: Dom. Quixote.

CAPPELI, P. (2001). Making the Most Online Recruiting. Harvard Business Review, 79 (3),139-146.

CARAMEZ, P. (2013). Como ter Sucesso no Linkedln. Lisboa: Lidel- Edições Técnicas, lda.

CARAMEZ, P. (2017). Estatísticas que não sabia sobre o Linkedln 2017. Recuperado em novembro 06, 2017 de https://pt.linkedin.com/pulse/estat\%C3\%ADsticas-que- n\%C3\%A3o-sabia-sobrelinkedin-2017-pedro-caramez.

CHIAVENATO, I. (2009). Recursos Humanos: O Capital Humano nas Organizações. (9a ed.). Rio de Janeiro: Elsevier.

CORONAS, T. \& Oliva, M. (2015)."E-Human Resources Management": Managing Knowledge People. Hershey: Idea Group Publishing.

COUTINHO, V. (2014). The Social Book: Tudo o que Você Precisa Saber Sobre Facebook. Lisboa: Editora Actual.

DAVISON, H. K., Maraist, C.C., Hamilton, R. H. \& Bing, M. N. (2012). To Screen or Not to Screen? Using the Internet for Selection Decisions. Employ Respons Rights J, 24(1), 1-21. 
DEKAY, S. (2009). Are business-oriented social networking web sites useful resources for locating passive jobseekers? Results of a recent study. Business Communication Quarterly, 72(1), 101-105.

DHAMIJA, P. (2012). E-Recruitment: A Roadmap Towards E-Human Resource Management. Journal of Arts, Science \& Commerce,3(2) 33-39.

EUROSTAT. Social media - statistics on the use by enterprises: https://ec.europa.eu/eurostat/statistics-explained/index.php/Social_media__statistics_on_the_use_by_enterprises

FAROLDI, L. (2007). Redes socials y Mercado de trabajo. Revista hispana para el análises de redes socials,13, 1-12.

FERNANDES, M. (2014). O uso das redes sociais no recrutamento externo em empresas portuguesas, dissertação em Gestão e Desenvolvimento de Recursos Humanos. Vila do Conde: Escola Superior de Estudos Industriais e de Gestão.

FISH, A. \& MACKLIN, R. (2004). Perceptions of executive search and advertised recruitment attributes and service quality. Personnel Review, 33(1), 30-54.

FRAGOSO, Alexandra. Introdução. In: FRAGOSO, Alexandra. A INFLUENCIA DAS REDES SOCIAIS NOS PROCESSOS DE RECRUTAMENTO E SELEÇÃO. 2017. Dissertação de Mestrado (Economia) - Faculdade de Economia Universidade do Porto, [S. I.], 2017.

GOMES, A. (2011). Recrutamento nas redes sociais On-line, Tese de Mestrado de Gestão de Recursos Humanos. Lisboa: Universidade técnica de Lisboa, Instituto Superior de Economia e Gestão.

LACOMBE (2011), Francisco José Masset; Recursos humanos: princípios e tendências. 2.ed. São Paulo: Saraiva.

MESKANICK, P. (2009). Critical Success Factors for Recruitment Process Outsourcing (RPO). Oil \& Gas Journal, 113(6), 8-11.

NIKOLAOU, I. (2014). Social Networking Web Sites in Job Search and Employee Recruitment. International Journal of Selection and Assessment. Rio de janeiro, p. 179-189.

PAPACHARISSI, Z. (2009). The virtual geographies of social networks: a comparative analysis of Facebook, Linkedln and ASmallWorld. New Media Society, 11(1,2), 199-220.

SANCHEZ, A., Granado, A. \& Antunes, J. (2014). Redes Sociais para Cientistas. Lisboa: Nova Escola Reitoria da Universidade Nova de Lisboa. 
SOUSA, M., Duarte, T., Sanches, P. \& Gomes J. (2006). Gestão de Recursos Humanos: Métodos e Práticas. (10a ed.). Lisboa: Lidel- Edições Técnicas, Ida.

THOMAS, S. \& Ray, K. (2000). Recruitment and the Web: High-Tech Hiring. Business Horizons, May-June

VIEIRA, M. (2010). Impacto das novas tecnologias no recrutamento nas empresas especializadas de Recrutamento e Seleção, tese de Mestrado em Gestão de Recursos Humanos. Lisboa: ISCTE- Business School, Instituto Universitário de Lisboa.

ZIDE, J., Elman, B., \& Shahani-Denning, C. (2014). Linkedin and recruitment: how profiles differ across occupations. Employee Relations, 36(5), 583-604. 


\section{Apêndice 1}

\section{Entrevista Recrutador A}

1. Caracterização do entrevistado: Quantos anos você tem? Trabalha com recrutamento e seleção a quanto tempo? Com qual segmento você atua hoje em dia?

R: Tenho 38 anos, trabalho com recrutamento e seleção tem mais ou menos 14 ou 15 anos e hoje trabalho com empresas do segmento de Indústrias e Serviços.

2. Como você considera a eficiência do Linkedln para os processos de R\&S?

R: Considero uma ferramenta complementar, acredito que não podemos depender só do Linkedln.

3. Quais os seus objetivos com o uso do Linkedln?

R: Uso para buscar candidatos para as minhas posições, me conectar com eles e entrar em contato. Também uso para ver o mercado, se alguma empresa esta contratando ou demitindo e também para fazer publicação de vagas.

4. Quais os níveis de posições que você recruta atualmente?

R: Média e alta gerência.

5. Quais você considera que são os piores problemas do Linkedln quando usado nos processos de R\&S?

R: O Linkedln, por causa das politicas de compliance, não consegue fazer determinadas buscas, como por exemplo contratar um negro, filtrar por 
gênero ou PcD. Dependendo da demanda que a gente recebe do cliente ficamos um pouco sem escolha.

6. Já se deparou com algum processo ou alguma situação em que o Linkedln não tenha sido eficiente para encontrar/filtrar candidatos?

R: Sim, depende do tipo de posição e senioridade. Para tech não é a melhor ferramenta; diversidade, nível de senioridade (vaga de produção fabril não funciona, só se for nível de gestão), assistente não funciona. Até analista júnior ou pleno fica complicado. Só vai achar a pessoa no Linkedln se é uma pessoa que já está antenada, "high potention". Eu já fiz uma posição para olhar para galinha que bota ovo e não para galinha de corte, uma pessoa que fica na fazenda, esses tipos posições é um gap muito grande.

7. Em uma escala de 0 a 5 , quanto você acredita que o Linkedln é eficiente para recrutar os níveis de profissionais citados abaixo:
a. Gerentes e Coordenadores - 5
b. Analistas plenos e sêniores - 4
c. Analistas juniores -3
d. Estagiários - 2

8. Quando o Linkedln não foi eficiente, que outras ferramentas e recursos você utilizou para buscar profissionais no mercado?

R: Entrevistas proativas, participar de feiras do segmento (ajuda a fazer networking e trocar cartão), ir para shopping/rua. Eu já abordei gente no Facebook e Instagram, quando a pessoa não aceitava no Linkedln. Eram posições que o cara não fica antenado no Linkedln e aí fui atrás no insta e Facebook para que eles respondessem. Eu já taquei também o nome da pessoa no google. Tiveram 2 casos que a pessoa respondeu, mas não deu muito resultado o Facebook/Intagram. Tem o Lusha, ferramenta boa para pegar telefone, mas esta diretamente atrelado ao Linkedln. Outra forma é olhar em revistas/noticias, ler sobre o tema e ver se encontra o nome de alguém interessante para a posição. 
9. Existia alguma diferença referente ao uso do Linkedln em outras consultorias que você trabalhou?

R: Igual, sem diferenças. Em outra consultoria o Linkedln era Recruiter e não o Premium então tinha essa ferramenta a mais, mas o uso era 0 mesmo. 


\section{Apêndice 2}

\section{Entrevista Recrutador B}

1. Caracterização do entrevistado: Quantos anos você tem? Trabalha com recrutamento e seleção a quanto tempo? Com qual segmento você atua hoje em dia?

R: Fiz 26 anos recentemente. Tem uns 3 anos mais ou menos que trabalho com recrutamento e seleção e hoje trabalho no segmento de Private Equity e Venture Capital.

2. Como você considera a eficiência do Linkedln para os processos de R\&S?

R: No geral acho muito eficiente, consegue ter um contato direto com as pessoas, consegue visualizar o perfil delas, já faz um filtro só por ali e chega numa entrevista com informações suficientes para ela ser direcionada. Acho que ele tem $80 \%$ de eficiência, dou nota 8 para plataforma.

3. Quais os seus objetivos com o uso do Linkedln?

R: Basicamente para encontrar candidatos, seja pelo filtro e abordando eles ou então publicando posições e aguardando envio de CV.

4. Quais os níveis de posições que você recruta atualmente?

R: De analista pleno até níveis de diretoria.

5. Quais você considera que são os piores problemas do Linkedln quando usado nos processos de R\&S? 
R: É um problema para quem não tem nenhum tipo de assinatura. Para quem não tem assinatura tem limite de quantas pessoas se conectar, quantas mensagens mandar, limite de pessoas que aparece por página e, mesmo com Premium, tem limite de caracteres na hora da conexão, nas buscas filtradas as vezes da problema em buscas grandes, quando coloca muito filtro, apenas buscas menores não da tanto problema.

6. Já se deparou com algum processo ou alguma situação em que o Linkedln não tenha sido eficiente para encontrar/filtrar candidatos?

R: Algumas vezes. Posições em regiões mais remotas. Exemplo, estou fazendo uma vaga que o foco é o Norte e tem um leque pequeno de pessoas, elas não têm tanto acesso. Outro exemplo foi uma posição de comprador específica para carnes, achei gente mas via que muita gente não conhecia a plataforma. Algumas posições mais operacionais ou em regiões fora do eixo Rio / São Paulo ou com menor grau de escolaridade ou regiões mais remotas. Pessoas mais qualificadas conhecem mas uma grande parcela não esta ali.

7. Em uma escala de 0 a 5 , quanto você acredita que o Linkedln é eficiente para recrutar os níveis de profissionais citados abaixo:

a. Gerentes e Coordenadores - 5 (dependeria da área)

b. Analistas plenos e sêniores -4

c. Analistas juniores -3

d. Estagiários - 2

8. Quando o Linkedln não foi eficiente, que outras ferramentas e recursos você utilizou para buscar profissionais no mercado?

R: Indicação, falar com pessoas conhecidas (networking offline), vagas.com (atendia pessoas mais juniores, como analista junior, trainee, pessoas com ate uns 3 anos de experiência); anuncio impresso (colocar em taxi, placa em algum lugar; mídia offline); Instagram, acabo divulgando no Instagram mas nunca cheguei a abordar ninguém pela plataforma. 
9. Existia alguma diferença referente ao uso do Linkedln em outras consultorias que você trabalhou?

R: Usavam bem menos, usava muita plataforma de histórico da consultoria e usavam um site de cadastro que vai para um sistema que fica um banco de dados. Usavam também o vagas.com. Lá eles usavam o Linkedln depois do networking e banco de dados deles. 


\section{Apêndice 3}

Entrevista Recrutador C

1. Caracterização do entrevistado: Quantos anos você tem? Trabalha com recrutamento e seleção a quanto tempo? Com qual segmento você atua hoje em dia?

R: Tenho 40 anos, trabalho com recrutamento e seleção desde 2008 e hoje vejo o segmento de energia e infraestrutura.

2. Como você considera a eficiência do Linkedln para os processos de R\&S?

R: Melhor ferramenta do mercado para fazer conexões e achar pessoas. É onde se tem a maior quantidade de pessoas dispostas a serem contatadas, não vejo caminho melhor para ser ou ser vista. Se postar uma vaga recebe vários currículos.

3. Quais os seus objetivos com o uso do Linkedln?

R: Acessar as pessoas e saber quem senta em cada cadeira.

4. Quais os níveis de posições que você recruta atualmente?

R: Normalmente de média a alta gerência.

5. Quais você considera que são os piores problemas do Linkedln quando usado nos processos de R\&S?

R: Filtro não é tão eficiente. 
6. Já se deparou com algum processo ou alguma situação em que o Linkedln não tenha sido eficiente para encontrar/filtrar candidatos?

R: Sim, algumas posições mais operacionais. Estudantes talvez não tenham tanto interesse na plataforma e acaba que o Linkedln não ajuda a recrutar esse tipo de profissional.

7. Em uma escala de 0 a 5, quanto você acredita que o Linkedln é eficiente para recrutar os níveis de profissionais citados abaixo:
a. Gerentes e Coordenadores - 5 (muito eficiente)
b. Analistas plenos e sêniores - 5 (muito eficiente)
c. Analistas juniores -4 (eficiente)
d. Estagiários - 3 (um pouco menos eficiente)

8. Quando o Linkedln não foi eficiente, que outras ferramentas e recursos você utilizou para buscar profissionais no mercado?

R: Indicação, bancos de dados que tinham mais informações que o Linkedln, como o vagas.com e bancos de dados das próprias empresas.

9. Existia alguma diferença referente ao uso do Linkedln em outras consultorias que você trabalhou?

R: Nenhuma diferença. 


\section{Apêndice 4}

\section{Entrevista Recrutador D}

1. Caracterização do entrevistado: Quantos anos você tem? Trabalha com recrutamento e seleção a quanto tempo? Com qual segmento você atua hoje em dia?

R: 25 anos de idade, mais ou menos 3 anos e meio de carreira em recrutamento e seleção e atuo na área de tecnologia.

2. Como você considera a eficiência do Linkedln para os processos de R\&S?

R: Ajuda muito, bem eficiente, se usar o Linkedln Premium é melhor ainda, sem o Premium é bem limitado.

3. Quais os seus objetivos com o uso do Linkedln?

R: Buscar candidatos alinhados as posições que estou fazendo e tentar conseguir um contato para entrevista-los.

4. Quais os níveis de posições que você recruta atualmente?

R: Já fiz muito cargo operacional de TI, de engenheiro por exemplo, mas hoje trabalho apenas com cargos de liderança de TI, como tech lead e coordenador para cima.

5. Quais você considera que são os piores problemas do Linkedln quando usado nos processos de R\&S?

R: Limite de abordagem, limite de convites que pode enviar. O chat não é tão fácil de usar, menos userfriendly. Questão de contato de $1^{\circ}, 2^{\circ}$ e $3^{\circ}$ 
grau, atrapalha não poder abordar alguém que não tem conexão. Limite de caracteres na abordagem, limite de conexões.

6. Já se deparou com algum processo ou alguma situação em que o Linkedln não tenha sido eficiente para encontrar/filtrar candidatos?

R: Sim, depende da posição. Por exemplo, vaga de tech tem muito profissional que não esta no Linkedln. Em tecnologia sinto pouca dificuldade com senioridade, tem menos opção de cargos mais baixos mas conseguia achar.

7. Em uma escala de 0 a 5 , quanto você acredita que o Linkedln é eficiente para recrutar os níveis de profissionais citados abaixo:
a. Gerentes e Coordenadores - 5
b. Analistas plenos e sêniores - 4
C. Analistas juniores -4
d. Estagiários - 3

8. Quando o Linkedln não foi eficiente, que outras ferramentas e recursos você utilizou para buscar profissionais no mercado?

R: As vezes, bem raramente, uso o BitHub, que é tipo um banco de dados de programação. Ja usei também portal de divulgação de vagas como Profissionais TI e Geek Hunter.

9. Existia alguma diferença referente ao uso do Linkedln em outras consultorias que você trabalhou?

R: Nunca trabalhei em outra consultoria. 


\section{Apêndice 5}

Entrevista Recrutador E

1. Caracterização do entrevistado: Quantos anos você tem? Trabalha com recrutamento e seleção a quanto tempo? Com qual segmento você atua hoje em dia?

R: Tenho 21 anos e estou como recrutadora tem apenas 1 ano, na área de tecnologia.

2. Como você considera a eficiência do Linkedln para os processos de R\&S?

R: No geral ajuda bastante, eficiente na maioria das vezes.

3. Quais os seus objetivos com o uso do Linkedln?

R: Encontrar profissionais e ver como esta o mercado.

4. Quais os níveis de posições que você recruta atualmente?

$R$ : Antes fazia vagas mais operacionais, como de desenvolvedor mas dava muito trabalho, o pagamento era menor e não tinha tanta gente no LinkedIn. Hoje faço vagas mais gerenciais e de liderança.

5. Quais você considera que são os piores problemas do Linkedln quando usado nos processos de R\&S?

R: Ele bloqueia conexões, Inmails são limitados, limite da quantidade de pessoas que pode se conectar, e o nosso trabalho é volume de 
abordagens. O filtro da uma atrapalhada também porque as vezes não funciona direito.

6. Já se deparou com algum processo ou alguma situação em que o Linkedln não tenha sido eficiente para encontrar/filtrar candidatos?

R: Sim, estou fazendo uma vaga que é para trabalhar em empresa do Brasil, ganhando em dólar e o salário acaba não sendo competitivo. $\mathrm{Na}$ hora de buscar profissionais, mesmo colocando o filtro do Brasil, o Linekdln mostra pessoas do exterior.

7. Em uma escala de 0 a 5 , quanto você acredita que o Linkedln é eficiente para recrutar os níveis de profissionais citados abaixo:
a. Gerentes e Coordenadores - 5
b. Analistas plenos e sêniores -5
C. Analistas juniores - 3
d. Estagiários - 2

8. Quando o Linkedln não foi eficiente, que outras ferramentas e recursos você utilizou para buscar profissionais no mercado?

R: As vezes uso o BitHub mas não vale muito porque demora muito então acabo pedindo indicação.

9. Existia alguma diferença referente ao uso do Linkedln em outras consultorias que você trabalhou?

R: Nunca trabalhei em outra consultoria. 


\section{Apêndice 6}

\section{Entrevista Recrutador F}

1. Caracterização do entrevistado: Quantos anos você tem? Trabalha com recrutamento e seleção a quanto tempo? Com qual segmento você atua hoje em dia?

R: 35 anos de vida com apenas 2 como recrutadora e olhando para 0 segmento de agronegócio.

2. Como você considera a eficiência do Linkedln para os processos de R\&S?

R: Bem eficiente para o trabalho que a gente faz.

3. Quais os seus objetivos com o uso do Linkedln?

R: Achar perfis bons e alinhados para as posições e buscar novos clientes para a consultoria.

4. Quais os níveis de posições que você recruta atualmente?

R: Cargos mais de especialistas, coordenadores, gerentes e diretores.

5. Quais você considera que são os piores problemas do Linkedln quando usado nos processos de R\&S?

R: Antes de entrar em consultoria, eu trabalhada como head de empregabilidade em uma sartup que era meio que parecida com o LinkedIn, mas tinha um diferencial que era o teste comportamental. Todas as pessoas que estavam cadastradas na base faziam esse teste e as empresas buscavam lá dentro baseado em soft skills também. O Linkedln 
não tem teste comportamental, sinto falta de ter informações de soft skills baseado em teste. O nosso teste na startup tinha $98,8 \%$ de assertividade. Minha sugestão seria ter um vídeo de apresentação de cada perfil.

6. Já se deparou com algum processo ou alguma situação em que o Linkedln não tenha sido eficiente para encontrar/filtrar candidatos?

R: Com certeza, a cultura do Linkedln dentro do agronegócio ainda pode ser melhorada. As vezes não tem todas as empresas e todos os profissionais, não tem uma boa base de dado. Além disso, vagas básicas, vagas de níveis mais inferiores, como auxiliar de mecânico, percebo que não tem muitos perfis cadastrados lá. Para algumas pessoas a cultura no Linkedln esta desde a faculdade e para outras não. Acredito que o segmento da pessoa e a área de atuação é um problema maior do que a senioridade do cargo.

7. Em uma escala de 0 a 5, quanto você acredita que o Linkedln é eficiente para recrutar os níveis de profissionais citados abaixo:
a. Gerentes e Coordenadores - 5
b. Analistas plenos e sêniores -4
c. Analistas juniores -4
d. Estagiários - 4

8. Quando o Linkedln não foi eficiente, que outras ferramentas e recursos você utilizou para buscar profissionais no mercado?

R: Sites de currículos e parcerias, como instituições de ensinos que formam esses profissionais.

9. Existia alguma diferença referente ao uso do Linkedln em outras consultorias que você trabalhou?

R: Não tinha diferença no uso não. 
